\title{
Design of a Cross-curricular Circuits Laboratory Experiment
}

\section{Mr. William Michael Delaney, University of Portland}

I am a recent graduate from the University of Portland where I received my Bachelors of Science in Mechanical Engineering in 2017. I am now attending the University of British Columbia working on my Masters of Engineering in Naval Architecture and Marine Engineering. I am expecting to graduate in 2018.

\section{Dr. Heather Dillon, University of Portland}

Dr. Heather Dillon is an Assistant Professor in Mechanical Engineering at the University of Portland. Her teaching focuses on thermodynamics, heat transfer, renewable energy, and optimization of energy systems. She currently leads a research team working on energy efficiency, renewable energy, and fundamental heat transfer. Before joining the university, Heather Dillon worked for the Pacific Northwest National Laboratory (PNNL) as a senior research engineer.

\section{Dr. Joseph P. Hoffbeck, University of Portland}

Joseph P. Hoffbeck is a Professor of Electrical Engineering at the University of Portland in Portland, Oregon. He has a Ph.D. from Purdue University, West Lafayette, Indiana. He previously worked with digital cell phone systems at Lucent Technologies (formerly AT\&T Bell Labs) in Whippany, New Jersey. His technical interests include communication systems, digital signal processing, and remote sensing. 


\section{Design of a Cross-Curricular Circuits Laboratory Experiment}

\section{Abstract}

The purpose of this research was to develop a laboratory module which introduces a mechanical engineering concept into an existing circuits laboratory module for a course taken by both mechanical and electrical students. This module was developed so mechanical engineering students would have a familiar concept they could relate to while conducting the circuits lab, making the lab more engaging for mechanical engineering students. For this module a Wheatstone bridge was paired with a strain gage to illustrate the mechanical concept of strain. To allow students to visualize this strain, the Wheatstone bridge was connected to an oscilloscope so that the change in voltage could be viewed and measured when the strain gage is deflected. This module allowed mechanical and electrical engineering students to learn concepts simultaneously from two very distinct fields of study. A student survey was developed and measured high student engagement in the topic of both circuits and Wheatstone bridge systems.

\section{Introduction}

This paper describes a pair of laboratory modules that students encounter in the mechanical engineering curriculum. The two laboratory modules have been developed to help scaffold knowledge and increase engagement in a circuits laboratory. The first module includes a bending beam with a strain gage that has been documented in a prior paper [1]. The second module introduces the same equipment to a circuits laboratory that is required for mechanical engineering students and adds a Wheatstone bridge circuit that students build. This crosscurriculum laboratory module is part of a larger effort by faculty and students to enhance the entire laboratory curriculum and learning experience for mechanical engineers. This enhancement includes the following facets:

1. Improve and modernize the technical skills acquired by students in laboratory courses.

2. Thoughtfully incorporate developmental skills, such as teamwork and communication, which are important for engineers.

The overall goal of the project is to improve how engineering students learn particular concepts which are pertinent throughout the four-year mechanical engineering curriculum [1]-[3]. It is possible to assess the success of these new laboratory modules through using evidence collected via surveys conducted after the lab the module was completed by students.

The current mechanical engineering curriculum requires students to take a 3 credit circuits class with a 1 credit laboratory. The course is required for both electrical and mechanical engineering students who often participate during their sophomore year. The purpose of this laboratory module was to combine a mechanical concept with an electrical one to help students appreciate the topic. The idea of this experiment builds on a laboratory which had been developed and printed online in 2003 by the University of California, Santa Barbara [4]. 
For this scaffolding experiment, a circuit was created where a strain gage is connected to a Wheatstone bridge and then, by way of a differential amplifier circuit, is connected to an oscilloscope. When the strain gage is deflected, the voltage output of the Wheatstone circuit changes and the deflection is visualized on the oscilloscope. This combination of separate concepts allows the knowledge of the circuit and strain gage to become more concrete for students. Past research has shown that scaffolding knowledge, or the laying of concepts from multiple disciplines, in education improves educational outcomes [2], [5]-[7]. Scaffolding is accomplished in this module because the mechanical concept of strain would be familiar to most of the mechanical engineering students at this point in the curriculum. Therefore, many students should be able to apply this knowledge to the new concept of Wheatstone bridges in the context of the circuits course.

This experiment also provides new context for electrical engineering (or other) students who also take part in the circuits class and lab. Through this lab module, they learn not only what a Wheatstone bridge is, but one real world application of a Wheatstone bridge. This can become valuable information for both the mechanical and the electrical engineer as this lab module will now allow them to create a device that will allow them to both visualize and measure strain.

\section{Background}

The ability for universities and other academic institutions to teach inter-disciplinary engineering effectively has increased over the past few decades. An example of this is shown in the progress made in several studies by Marasco. In each of the studies it was found that when two or more disciplines were implemented into the curriculum in order to teach the students a subject, the students actually learned the material better than if the subject was taught by itself [6]. In another thesis presented by Rigby, it was found that when students were presented with multiple representations, or multiple sides of the same concept(s), that the students had a better understanding of an ill-defined concept [8]. A summary of inter-disciplinary engineering laboratory experiments is shown in Table 1.

Table 1. Summary of interdisciplinary laboratory modules from the literature.

\begin{tabular}{l|l|l|l} 
Author & Year & STEM Disciplines & Laboratory Topic \\
\hline Marasco [6] & 2013 & EE \& STEM & \\
\hline Rigby [8] & 2009 & CS \& EE & Threat analysis \\
\hline Roppel [9] & 2000 & EE \& CS & Laboratory sequence \\
\hline This Study & 2017 & EE \& ME & Strain gages in circuits lab \\
\hline
\end{tabular}

It is this concept of creating a better understanding of a complex subject, by using two disciplines in the same module, that generated the idea for the new circuits module. Following the success of other new scaffolding laboratory modules [1]-[3], it was decided to create a laboratory module that helped mechanical engineers in circuits. 


\section{Equipment Design}

The concept for a circuits module that builds on a prior mechanical engineering laboratory led to a specific design process for the new laboratory. The research team decided that the best circuits lab to implement the concept of strain was a Wheatstone Bridge. This was determined based on the wide use of strain gages in industry. A strain gage acts as a resistor and can be placed in a Wheatstone Bridge as the variable resistor. When placed in the Wheatstone bridge and then deflected, a change in voltage occurs which can be measured by using a multimeter.

To reduce cost, it was decided that all of the strain gages used in this new laboratory module would have a resistance of $350 \Omega$ so that this laboratory module could use hardware from previously developed bending modules for a Material Science class [1]. These bending modules included aluminum bars with $350 \Omega$ strain gages already attached. It was known that in order to balance the Wheatstone bridge, the resistor in series with it would have to be $350 \Omega$, while the other two should equal each other. So, a set of $350 \Omega$ precision resistors were purchased and when they arrived a series of tests were conducted to determine which would work best. The test circuit can be seen in Figure 1, where $R_{G}$ is the $350 \Omega$ strain gage, $R_{2}$ is a $350 \Omega$ precision resistor, and $\mathrm{R}_{1}=\mathrm{R}_{3}$ and are equal to either $350 \Omega, 330 \Omega$, or $360 \Omega$.

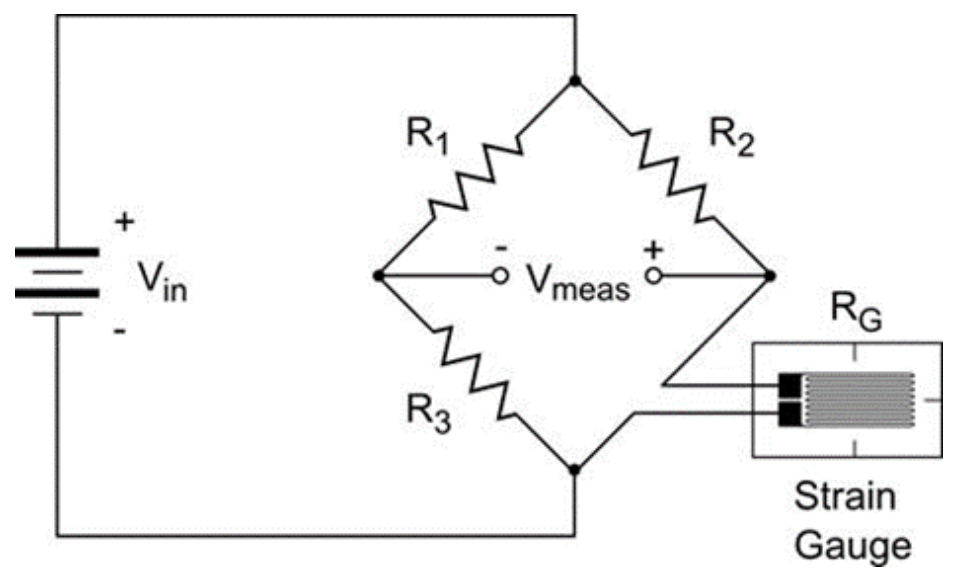

Figure 1: Wheatstone Bridge with Strain Gage Lab Test Setup.

These tests were relatively simple. They involved creating a Wheatstone Bridge where the variable resistor was a $350 \Omega$ strain gage attached to a 6061-T6 aluminum bar mounted on a steel base to fix one end. The Wheatstone bridge included one additional $350 \Omega$ precision resistor directly in series with the strain gage. The other two resistors were alternated between either $350 \Omega$ precision resistors, $330 \Omega$ resistors and $360 \Omega$ resistors. These resistors were chosen as they were the closest in resistance to the strain gage that were immediately available. All of the results of these design tests were similar, confirming that all of them would work for a laboratory module. The design process also determined that an amplifier was required for students to measure the voltage using standard multimeters.

Students use a digital multimeter (DMM) to measure the voltage on the bridge and then to measure the output of the differential amplifier. In addition, they use the oscilloscope to measure 
the output of the differential amplifier so that we can observe the changes in strain while the bar oscillates and measure the frequency of oscillation.

Prior work at the University of California had developed some elements of a lab like this, and the system here enhances this circuit for visualization by students [4]. This existing laboratory module used a strain gage connected to a Wheatstone bridge and then attached to an op-amp circuit such that the change in voltage could be visualized on an oscilloscope. Our module modifies the design to use resistors of $350 \Omega$, and $330 \Omega$.The op-amps were re-designed to use a LM324 op-amp. The power supply voltages in the system were increased to $\pm 12 \mathrm{~V}$ to make the output easier to read with a standard oscilloscope. The final circuit can be seen in Figure 2. With the oscilloscope set to DC coupling, a clear signal can be observed on the oscilloscope that moves in response to bending the aluminum bar.

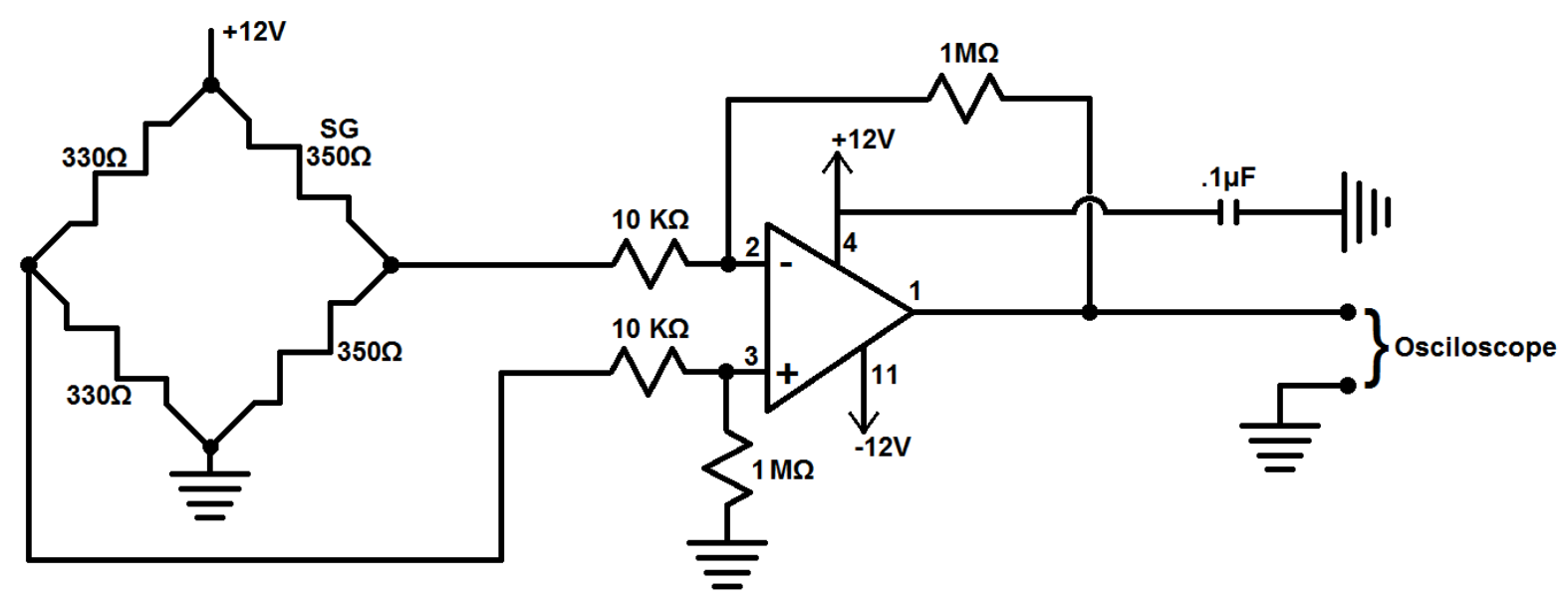

Figure 2: Final Circuit Diagram for Newly Designed Laboratory Module.

Each laboratory station requires one aluminum bar with a mounted strain gage, but two laboratory stations could share a mount (see Figure 3). This would keep the cost of the overall laboratory low while allowing for most of the bending modules to be borrowed from a currently existing laboratory module. A breakdown of the overall cost of each strain gage module can be found in Table 2. 


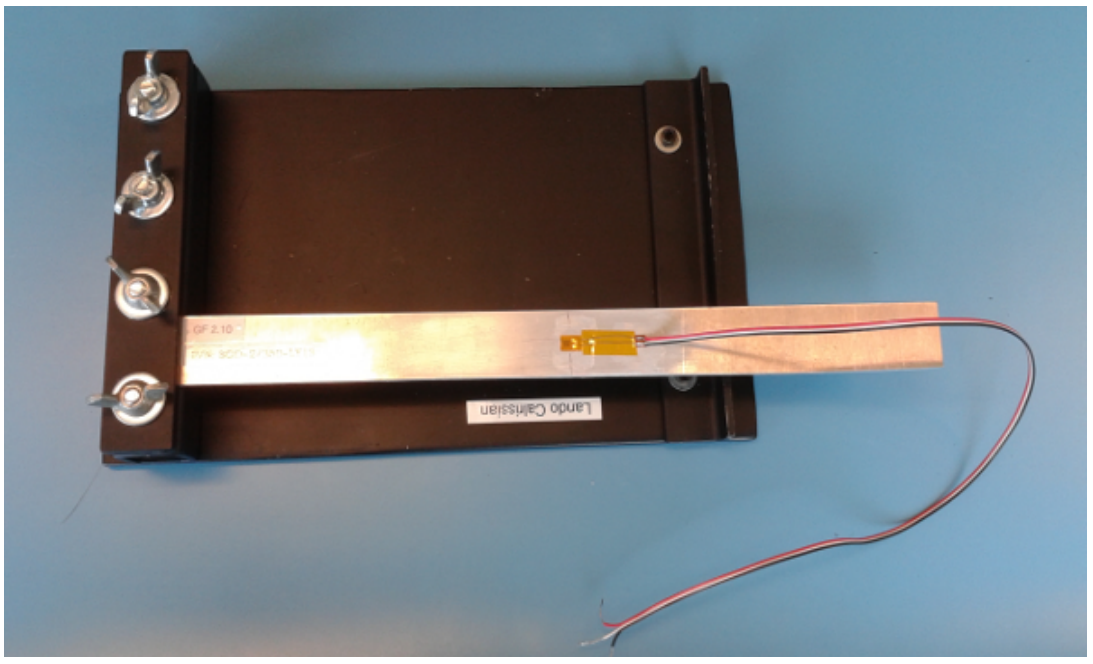

Figure 3: Mount for the Aluminum Bar with Strain Gage

Table 2: Summary of components and costs associated with the Circuits strain gage module.

\begin{tabular}{|c|c|c|}
\hline Component & $\begin{array}{c}\text { Part Number/Serial } \\
\text { Number }\end{array}$ & Cost per Module \\
\hline $\begin{array}{l}\text { Steel Base - Large } \\
\text { Rectangular Tubes }\end{array}$ & $* 6527 \mathrm{~K} 364$ & $\$ 15.94$ \\
\hline $\begin{array}{l}\text { Steel Base-Medium } \\
\text { Rectangular Tube }\end{array}$ & $* 6582 \mathrm{~K} 43$ & $\$ 7.94$ \\
\hline $\begin{array}{l}\text { Steel Base - Small } \\
\text { Rectangular Tube }\end{array}$ & $* 6582 \mathrm{~K} 22$ & $\$ 8.83$ \\
\hline Steel Base - Steel Bar & *8910K383 & $\$ 2.75$ \\
\hline Aluminum Bar & $* 9872 \mathrm{~T} 57$ & $\$ 12.70$ \\
\hline $350 \Omega$ Strain Gage & $* *$ SGD-5/350-LY13 & $\$ 7.50$ \\
\hline $3 \times 350 \Omega$ precision resistors & **71-PTF56350R00BZEK & $\$ 6.45$ \\
\hline $2 \times 10 \mathrm{k} \Omega$ resistors & & Available in lab \\
\hline $2 \times 1 M \Omega$ resistors & & Available in lab \\
\hline $0.1 \mu F$ Capacitor & & Available in lab \\
\hline LM 324 Op amp & 595-LM324AN & $\$ 0.39$ \\
\hline Total & & $\$ 62.50$ \\
\hline
\end{tabular}

*Minimum amount of material required before machining and assembly. Based on McMaster materials and pricings.

**Based on prices from suppliers.

\section{Wheatstone Bridge Results}

The overall results of this research involve two parts. The first includes how closely the output results of the module resembles the theoretical values calculated. The first set of results were promising as the theoretical values ranged within a 0 to $12 \%$ error range with the values 
calculated through this module. These benchmark results were calculated using a P3 Strain Indicator. The readings on an oscilloscope are shown in Figure 4.

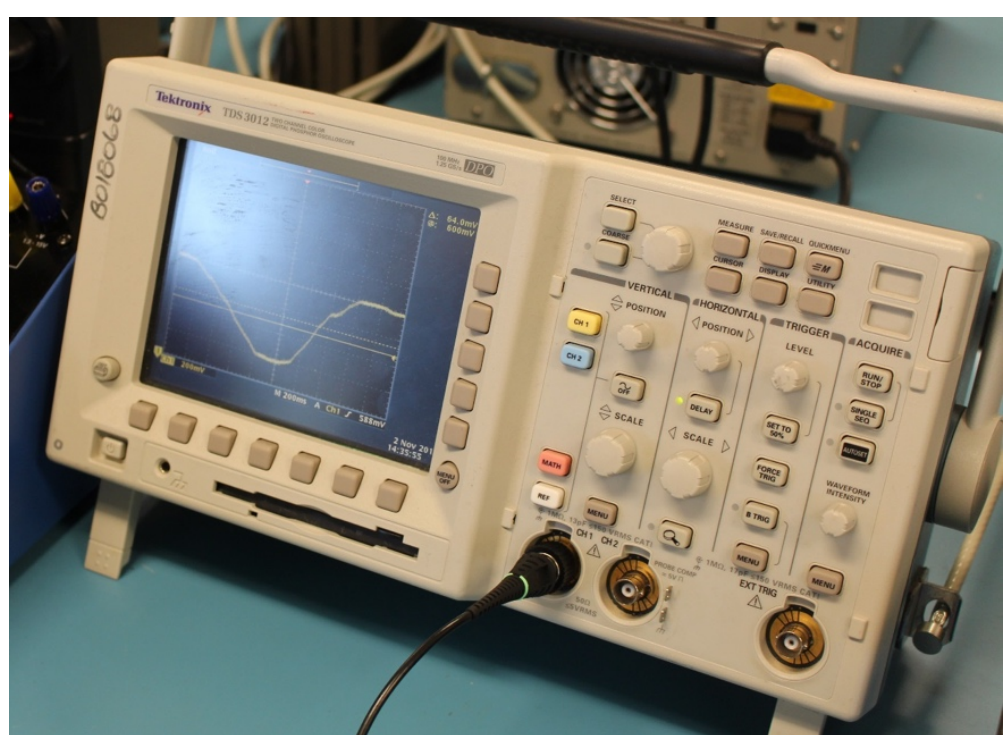

Figure 4: Example of the results on an Oscilloscope.

During the first implementation of this laboratory module, students were able to accurately replicate the experiment with results similar to both the theoretical strain and the experimental strain. This demonstrates the overall purpose of this experiment which is to allow students to confirm the data collected to that actual theory of the lab experiment itself while learning about the new concept of a Wheatstone Bridge in the process.

Typically the resistance of the strain gauge increases by about $0.5 \mathrm{Ohm}$ when the bar is bent down, which causes about $2 \mathrm{mV}$ change in the voltage on the bridge, and about $200 \mathrm{mV}$ change at the output of the op amp. The computed value of strain is typically about $700 \mathrm{e}-6$ (in/in) when students use the DMM to measure the resistance of the strain gauge directly, and we compute about 760e-2 (in/in) when the DMM is used to measure the voltage on the bridge. We also measure about 760e-2 (in/in) when we use the DMM to measure the voltage at the output of the differential amplifier, so all the methods compare well. The actual strain depends on how hard the bar is pressed, and so it varies a bit for each student group.

The oscilloscope is used to measure the voltage at the output of the op amp, which could be used to compute the strain, but during the lab students use the oscilloscope to measure the oscillation frequency after the bar is pressed and then suddenly released. Students typically measure the oscillation frequency at about $31 \mathrm{~Hz}$.

\section{External Observer Assessment}

In the Fall of 2016, this laboratory experiment was run for the first time as seen below in Figure 5, however most students were electrical engineers. In the Spring of 2017 the experiment module 
was run for the first time with primarily mechanical engineering students. To understand how the new module worked for students, an outside educational expert observed the classroom.

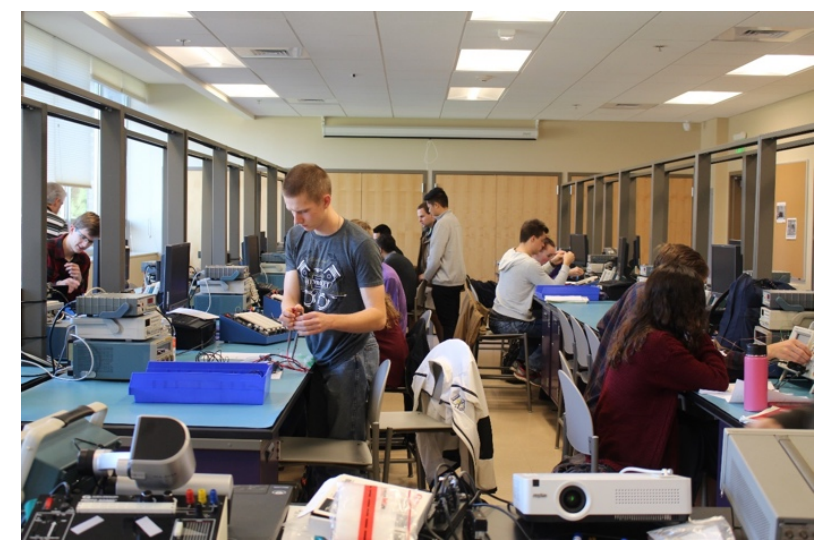

Figure 5: Students Conducting Laboratory Experiment for the First Time.

The expert observer made the following observations about the laboratory module.

- The observer asked most students if they were experiencing this sequence as an experiment or as a hands-on demonstration of EE/Circuits principles (that is, is the outcome pre-determined, or are you testing an hypothesis - both are really important, but "experiment" is often used sloppily, when the outcome is not really in doubt in a lab experience). All but one pair said it was a demo, an important one, and that they were very glad to be able to see in action what they had read about and heard in circuits lectures.

- A handful of students noted that the labs seemed generally a bit ahead of the lectures, so they weren't always aware of why they were stuck when they got stuck.

- Two lab partners noted they had not kept up with reading or pre-lab tasks and so were floundering in this lab, and had to ask several procedural questions.

- One pair said they thought it was more of an experiment than a demonstration, but had no answer to the question "what are you trying to find out or to test in this experiment? What are some different things that could happen?"

- All students who were asked (24 out of 28) said they felt equipped by pre-lab work and previous labs to think their way out of unexpected gage readings or other occurrences.

- In this observation, all who were noted encountering problems with the circuit went back to their original checklist given by instructor to make sure the set-up for the various implements matched what was described in instructions given.

- Each student present, even those who self-identified as inadequately prepared, appeared confident that they could ask the teacher for help in moving forward.

The observations did not clearly help the research team understand if the students had gathered more knowledge about strain and how a Wheatstone bridge works, but it provided important insights for improving the laboratory modules. These include more clearly communicating the purpose of the experiment, encouraging the pre-lab work, and allowing the students a more openended test to perform. 


\section{Student Survey Assessment}

An optional student survey was also conducted to determine how effective this experiment was on overall student learning for the subject of Wheatstone Bridges and the concept of strain. This questionnaire covered questions ranging from how much control they had on the overall lab itself, to how confident they felt in their competency in the material itself. Many of the questions were consistent with prior survey questions tied to understanding the larger curriculum modification as outlined in prior papers [1-3].

All of the questions were scored on a Likert scale of 1 to 5 where 1 was the worst ranking and 5 was the best ranking. The laboratory modules that were created or modified in this study are marked with a *. In general, when compared to other more traditional laboratories, the authors consider a higher Likert score for student engagement to be successful. Any mean score higher than 3.0 is stronger than neutral and indicates some preference from the survey respondents.

In the Spring of 2017, 51 students completed the survey. Most were mechanical engineers (45) and the rest were electrical engineers or other majors. The students from Fall 2016 interacted with a preliminary version of the new modules and the results were not considered to be consistent for the surveys.

The majority of students reported that they had a great deal of control over the experiment. The average of all the responses was 3.35 with standard deviation of 1.01 . This data has been summarized in Figure 6.

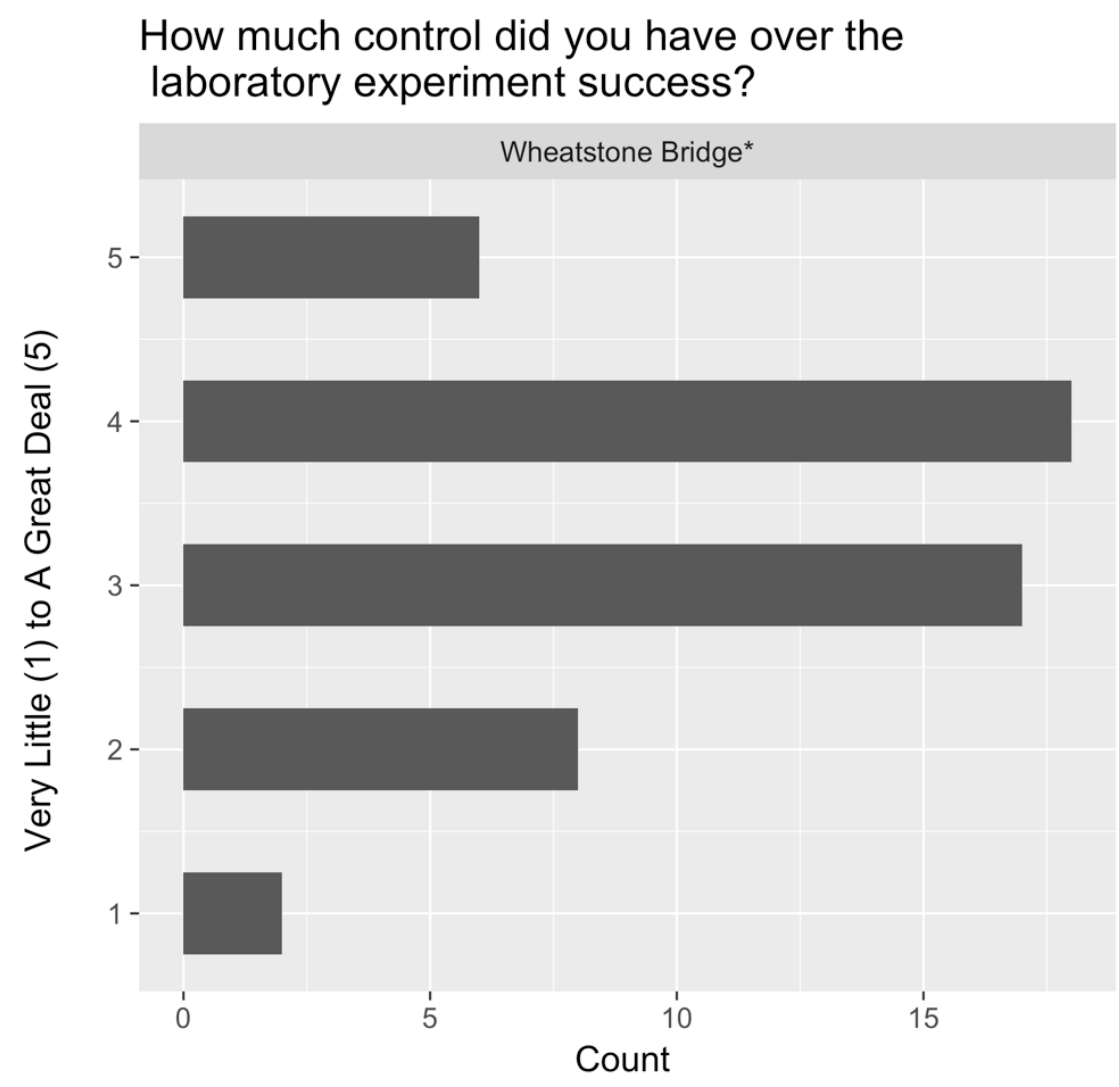


Figure 6: Student report of overall control of the Wheatstone Bridge Experiment

The next question on the questionnaire asked the students how well they felt invested in learning the material. This question was directed toward the strain gage, the Wheatstone bridge, and more traditional circuits topics like op-amps and oscilloscopes. Overall the laboratories were rated by students with a mean of 3.29 and standard deviation 1.62. The Wheatstone bridge module was ranked higher with an average of 3.51 and standard deviation of 1.44. The strain gage module was not as highly ranked, but had a good average with 3.55 and standard deviation of 1.58 . The results can be found below in Figure 7.

\section{How invested did you feel about learning the laboratory material?}

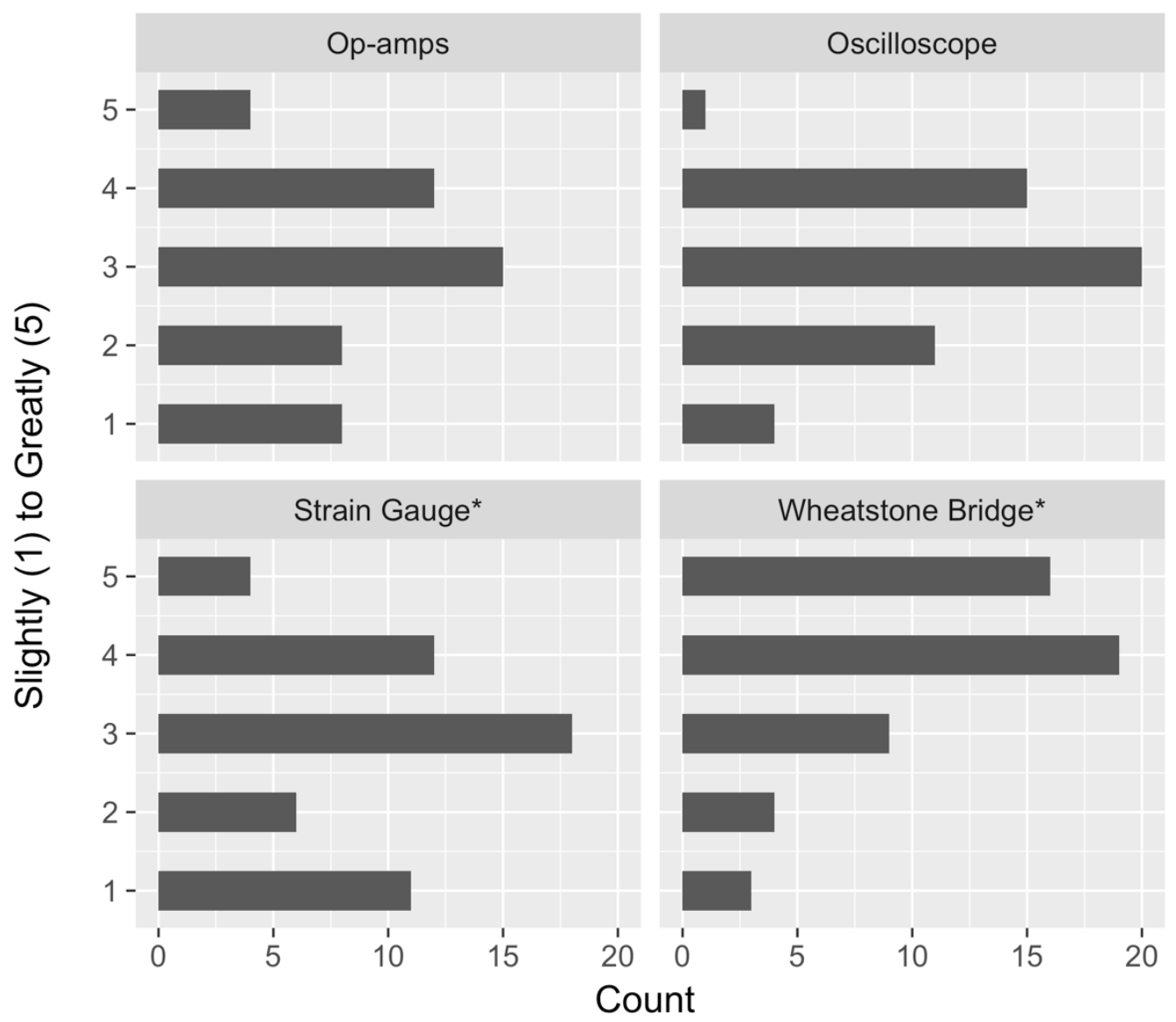

Figure 7: Student Investment Learning for Strain Gages. The laboratory modules that were created or modified in this study are marked with a *.

The next question covered how competent each student felt he or she would be able to apply the material learned in this laboratory in the real world. The results of this data can be found in Figure 8 . The Wheatstone bridge concepts were again ranked highly by students with a mean of 3.31 and standard deviation of 2.17. The overall list of concepts had an average of 3.64 and standard deviation of 2.32 indicating most students did feel more competent on most topics. 
For each subject covered in the laboratory, each student was asked if they felt that their overall competency was increased. They overwhelmingly responded yes (57\%) to indicate competence had increased for all lab concepts.

\section{How competent do you feel} on this material?

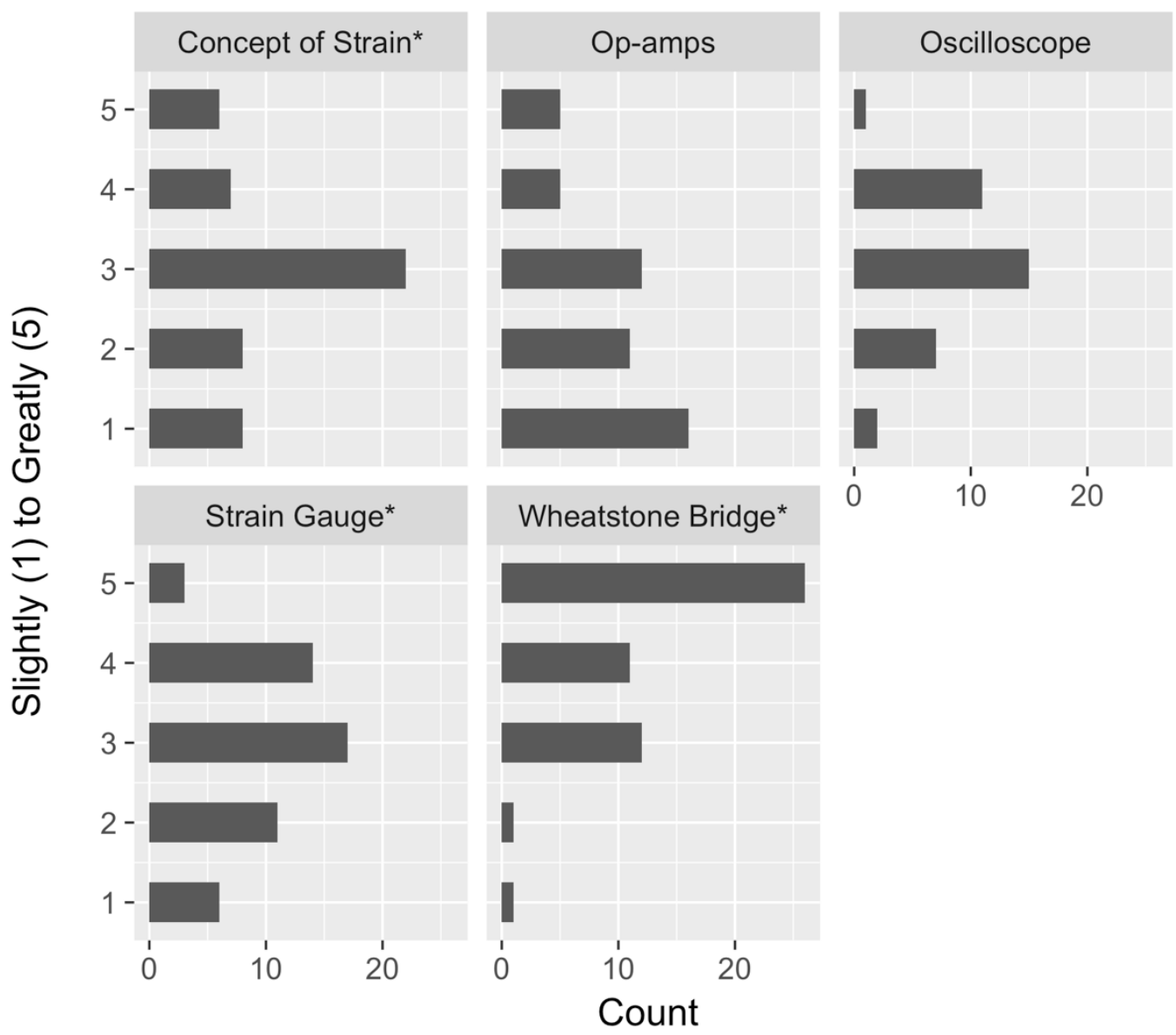

Figure 8: How competent students felt with different concepts covered in the laboratory. The laboratory modules that were created or modified in this study are marked with a *

The next question asked to students if they clearly saw the connection between the predominantly mechanical concepts with the electrical concepts. This question was asked because seeing the connection between the two subjects, and therefore learning the main material of the laboratory, was the key point of the new laboratory modules in the circuits course. As shown in Figure 9, this goal was primarily accomplished. In this figure, a 1 indicates that there was little connection while a 5 indicates that the connection between the two subjects was made and therefore this laboratory was a success. The mean response was 3.54 with a standard deviation of 0.99 . 


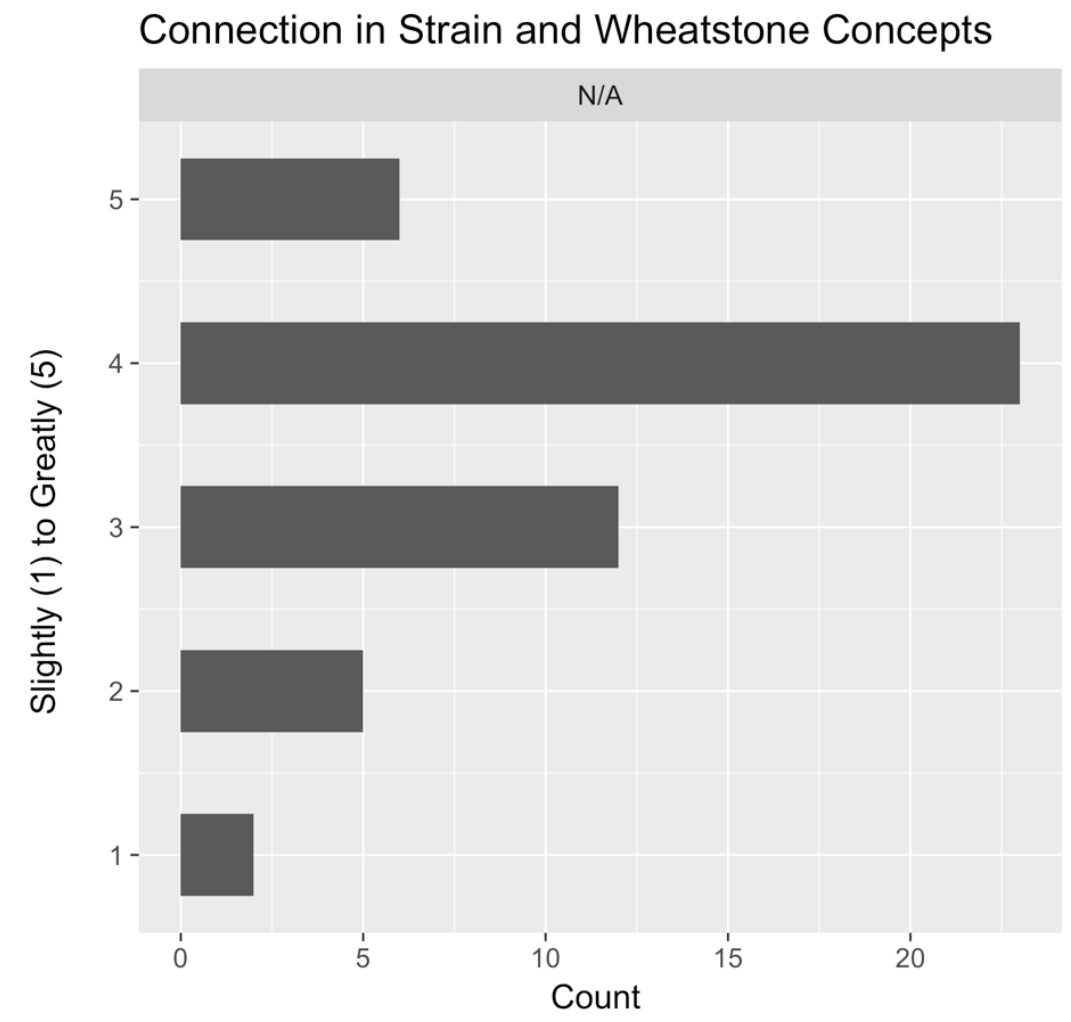

Figure 9: Overall Connection Between Mechanical and Electrical Concepts

The final question asked how engaging the overall laboratory experiment was compared to the earlier experiments in the semester. The purpose of this question would help the engineering department determine which experiments they should focus on in the future. The results of this question can be found in Figure 10. The overall response for all modules was 3.38 with standard deviation 1.09. The response for the Wheatstone bridge module averaged 3.45 with standard deviation 1.31 , which was higher than most of the laboratory modules. 


\section{Laboratory Engagement}

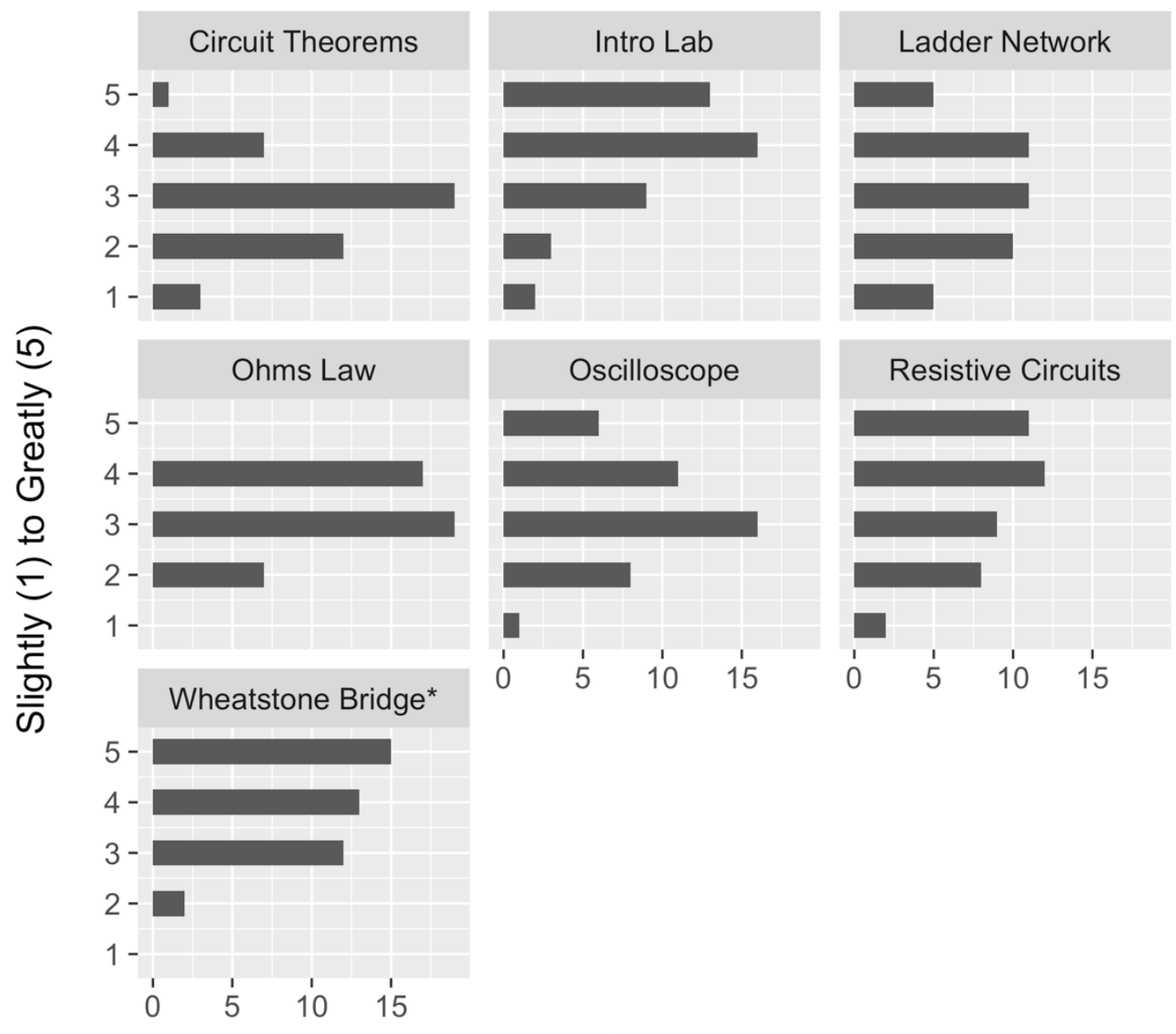

Count

Figure 10: Student Engagement in Laboratory Modules in Course. The laboratory modules that were created or modified in this study are marked with a*.

In general the Wheatstone bridge module was ranked highly by the students. The strain gage aspects of the new laboratory were not ranked as highly. This may be a reflection of the fact that most of the mechanical engineering students were already familiar with this equipment and found the material to be a bit of a "review", that might be considered less engaging. Overall the new Wheastone bridge module seems to have been well received by the students, particularly mechanical engineering students. Although not independently measured, the student selfreported confidence in the topics explored indicates improved learning as part of the modules.

\section{Conclusions}

An inexpensive experiment was created that combines bending modules with attached strain gages and a Wheatstone bridge circuit connected to an oscilloscope. It was designed such that when the bending module was deflected, a change of voltage would appear on the oscilloscope and the macrostrain could be calculated and visualized. 
Students in circuits laboratory tested this module in the Fall of 2016 and Spring semester of 2017 and the educational methodology was a success. Students, especially mechanical engineering students, reported that the combination of mechanical and electrical concepts increased their overall understanding of the electrical concepts as well as how they could be applied in the real world. They also reported higher engagement and control in the Wheatstone bridge portion of the experiment than in most other laboratory experiments.

Future work will include adjusting this module to maximize the potential of overall success in student learning as well as success in student learning in other circuits laboratory modules. This may include adjusting the modules to improve open-ended outcomes, and testing student learning with analysis of exam and quiz results.

\section{References}

[1] K. Lulay, H. E. Dillon, K. E. Eifler, T. A. Doughty, D. Anderson, and J. I. B. De Jesus, "Increasing engagement in materials laboratory with backward design and quadcopters," in ASEE Annual Conference and Exposition, Conference Proceedings, 2017, vol. 2017June.

[2] H. Dillon, N. Schmedake, K. E. Eifler, T. A. Doughty, and K. Lulay, "Design of a curriculum-spanning mechanical engineering laboratory experiment," in ASEE Annual Conference and Exposition, Conference Proceedings, 2016, vol. 2016-June.

[3] T. A. Doughty, H. Dillon, K. Lulay, K. E. Eifler, and Z. Y. Y. Hensler, "Design and implementation of an aspirational ethics laboratory course," in ASEE Annual Conference and Exposition, Conference Proceedings, 2017, vol. 2017-June.

[4] U. of California, "Laboratory 3: Strain Gage Sensors," Santa Barbara, CA, 2003. http://www.ni.com/pdf/academic/us/me104_lab3_2003.pdf

[5] R. D. Pea, "The Social and Technological Dimensions of Scaffolding and Related Theoretical Concepts for Learning, Education, and Human Activity," J. Learn. Sci., vol. 13, no. 3, pp. 423-451, Jul. 2004.

[6] E. A. Marasco, "Development of a CDIO-Based Creative Cross-Disciplinary Curriculum and Associated Projects for Elementary Engineering Education," Sep. 2013. https://prism.ucalgary.ca/handle/11023/1005

[7] S. Hsi and A. M. Agogino, "Scaffolding knowledge integration through designing multimedia case studies of engineering design," in Proceedings Frontiers in Education 1995 25th Annual Conference. Engineering Education for the 21st Century, 1995, vol. 2, p. $4 \mathrm{~d} 1.1-4 \mathrm{~d} 1.4$.

[8] S. E. Rigby, "The efficacy of cross-discipline representations for ill-defined IAS concepts," Purdue University, 2009. https://docs.lib.purdue.edu/dissertations/AAI3378851/

[9] T. A. Roppel, J. Y. Hung, S. W. Wentworth, and A. S. Hodel, "An interdisciplinary laboratory sequence in electrical and computer engineering: curriculum design and assessment results," IEEE Trans. Educ., vol. 43, no. 2, pp. 143-152, May 2000. 